\title{
1 A bioindicator assessment framework of river ecosystem 2 health and the detection of factors influencing the health 3 of the Huai River Basin, China
}

4

\author{
Jun Xia ${ }^{1}$, Yongyong Zhang ${ }^{2, *}$, Changsen Zhao ${ }^{3}$, Stuart E. Bunn ${ }^{4}$
}

${ }^{1}$ State Key Laboratory of Water Resources and Hydropower Engineering Science, Wuhan University, Wuhan, 430072, China

${ }^{2}$ Key Laboratory of Water Cycle and Related Land Surface Processes, Institute of Geographic Sciences and Natural Resources Research, Chinese Academy of Sciences, Beijing, 100101, China (Corresponding author). E-mail: zhangyy003@gmail.com.

${ }^{3}$ State Key Laboratory of Remote Sensing Science, Jointly Sponsored by Beijing Normal University and the Institute of Remote Sensing Applications of Chinese Academy of Sciences, Beijing 100875, China.School of Geography, Beijing Normal University, Beijing 100875, China

${ }^{4}$ Australian Rivers Institute, Griffith University, Brisbane, Queensland, Australia

\section{Abstract}

River ecosystem health assessments are a hot topic in global water resources management. The Huai River Basin is a representative basin faced with serious environmental problems due to high water pollution and numerous water projects. Comprehensive investigation of the factors affecting river ecosystem health is an urgent precursor to the successful management of the Huai River Basin. Based on a series of aquatic ecosystem indicators, monitoring and standards, such as phytoplankton, zooplankton and benthic macroinvertebrate data, an assessment framework of river ecosystem health is proposed using a multi-step gray correlation evaluation method. Environmental impact factors including climate, land cover, edaphic factors, hydrology, water projects and water quality were identified using the Kruskal-Wallis test and distance-based redundancy analysis method. The ecosystem was found to be sub-healthy with $44 \%(31 / 71)$ of sites in a healthy condition, 51\% (36/71) sub-healthy and $5 \%(4 / 71)$ unhealthy. Climate and hydrology were the dominant factors that together contributed $37.5 \%, 24.1 \%$ and $6.9 \%$ of the variation in phytoplankton, zooplankton and benthic macroinvertebrates, respectively. The main variables affecting variation were minimum temperature, relative humidity, solar radiation, and the magnitude, frequency, duration and timing of monthly runoff. Together, these variables 
1 explained $24.5 \%$ of the variation in the ecosystem health of the whole river. Thus, to improve river ecosystem health in the basin, the regulation of dams and sluices should give priority to ecological outcomes and the threat of climate change should not be underestimated. This study provides a blueprint for ongoing ecological monitoring and restoration programs in China and is expected to be a successful case and reference to transition from water quantity management to river health management in the Huai River Basin.

Key words: River ecosystem health; multi-step gray correlation method; multivariable analysis; Huai River Basin

\section{Introduction}

River ecosystem health assessments are one of the hot topics in global water resources management (Karr 1999; Arthington et al. 2010). Furthermore, it is an urgent task in a transition from water quantity management to water quality management, and even river health management in China (Meng et al. 2009; Liu and Liu 2009). According to the report "Rivers at Risk: Dams and the future of freshwater ecosystems" from 2004, there were 21 river basins in the world with dramatically degraded ecosystems, and the Yangtze River in China was one of the top three (WWF and WRI 2004). In China, the ecosystems of 8 major river basins have been destroyed by pollution, and the percentage of sub-healthy and unhealthy rivers in 2010 was $62.9 \%$ in the Hai River Basin, $59.5 \%$ in the Liao River Basin, 58.1\% in the Huai River Basin, 52.4\% in the Songhua River Basin, $31.8 \%$ in the Yellow River Basin, $11.4 \%$ in the Yangtze River Basin and $15.1 \%$ in the Pearl River Basin, based on the assessment of traditional water quality indices (EPAC 2002, 2010). Preserving and repairing river ecosystem health will promote economic and social sustainability and have consequently been identified internationally as research priorities (Rapport et al. 1998; Norris and Thoms 1999). River ecosystem health assessments and the detection of environmental impact factors will provide a foundation for river restoration and will improve basin sustainability (Meng et al. 2009).

An ecologically healthy river is a river that retains the major ecological features and functions of a river (Norris and Thoms 1999; Liu and Liu 2009). Currently, 
1 biological methods have risen to prominence in the assessment of river condition,

2 having gradually replaced traditional water quality assessment techniques (Norris and

3 Thoms 1999; Wright et al. 2000). Examples of biological methods include the River

4 Invertebrate Prediction and Classification System (RIVPACS) (Wright et al. 2000), the

5 Australian River Assessment System (AUSRIVAS) (Simpson and Norris 2000) and the

6 Benthic Invertebrate Community Structure (BEAST) (Reynoldson et al. 1997). The

7 biological approach compares the actual river species with the natural species in an

8 undisturbed river. However, application of this method is restricted by high data

9 requirements and the existence of an undisturbed river for comparison, which is increasingly rare, especially in China (Norris and Thoms 1999). Alternatively, indicator assessment approaches identify the social benefits of riverine development in addition to the benefits of preserving an ecosystem's natural structure and functions (Rapport et al. 1998; Fairweather 1999). The approach involves the selection and assessment of some characteristic indicators, followed by comparisons with established standards to quantify the health status of an ecosystem. Indicators should represent all aspects of the ecosystem, including aquatic species, chemistry and physical structure. This method better considers the integrity and diversity of an ecosystem and comprehensively reflects ecosystem health, and it has been used to assess river ecosystems globally. Examples include the index of biological integrity (IBI) (Karr 1981); the riparian, channel and environmental (RCE) inventory (Petersen 1992); and the index of stream condition (ISC) (Ladson et al. 1999). The widespread application of this method is attributable to its low data requirements.

River ecosystem health assessment is an urgent issue in China that faces many challenges, such as high spatial heterogeneity in large river systems, rapid development of the regional economy and population growth, the high density of water engineering projects and increasingly serious water pollution. The Huai River Basin is representative of Chinese rivers, with conflicts and tradeoffs between high population densities, economic development and environmental sustainability. A comprehensive assessment of river ecosystem health in the Huai River Basin would expedite the successful implementation of an integrated river basin management strategy and transition from water quantity management to river health management. Previous investigations were 
1 and it is a new challenge to assess river ecosystem health based on biological indicators.

2 This study investigated the spatial distribution and abundance of phytoplankton,

3 zooplankton and benthic macroinvertebrates at 71 sites in the Huai River Basin. The

4 objectives of this study are (1) to propose an integrated river ecosystem health

5 assessment framework for the Huai River Basin based on multiple bioindicators using

6 the multi-step gray correlation method; (2) to analyze the species composition and

7 assess the spatial distribution of ecosystem health status of the Huai River Basin; and

8 (3) to identify the environmental factors that influence the variation of river ecosystem

9 health using nonparametric multivariate analysis. This study is expected to provide the basis for river monitoring and restoration programs that incorporate bioindicators and support water resource planning and sustainable development in the Huai River Basin.

\section{Material and methodology}

Study area

The Huai River Basin $\left(30^{\circ} 55^{\prime}-36^{\circ} 36^{\prime} \mathrm{N}, 111^{\circ} 55^{\prime}-121^{\circ} 25^{\prime} \mathrm{E}\right)$ is located in eastern China between the Yangtze River Basin and the Yellow River Basin (Figure 1). There are two main sub-basins, the $190,000 \mathrm{~km}^{2}$ Huai River Drainage area and the $80,000 \mathrm{~km}^{2}$ Yishusi River Drainage area. The Huai River Basin lies in the south-north climate transition zone with approximately $888 \mathrm{~mm}$ mean annual precipitation and $8.35 \times 10^{11} \mathrm{~m}^{3}$ mean annual runoff.

The Huai River Basin is the sixth largest river basin in China, with an average population density of 623 person $/ \mathrm{km}^{2}$, which is approximately 4.5 times the national average. More than 5,700 dams and 5,000 floodgates have been constructed for flood control and water supply (Zhang et al. 2010). The industry boom in the basin, including paper mills, chemical plants and breweries, further threatens river health due to poor sewage disposal practices. Many ecological and environmental problems are emerging; for example, river fragmentation, lake and wetland shrinkage, loss of biodiversity and reduced water quality are all associated with declining ecological function. Previous studies in the Huai River Basin paid more attention to hydrology (Xia et al. 2011), environment and the impact of human activities, and ecological monitoring and assessment studies has been insufficient. A comprehensive assessment of river 
1 ecological condition and an understanding of the main influential factors determing river health will be important precursors to environmental improvement in the basin.

Data selection

Ecological sample sites and metrics. Seventy-one sample sites were chosen based on the monitoring stations for routine hydrology and water quality assessments (Water Resources Bulletin of the Huai River Basin, 1997-2008), which are distributed in the Hongru River, Shaying River, Guo River, Huai River, Southern mountain rivers, Beijing-Hangzhou Grand Canal and Yishusi River (Figure 1). Sampling was conducted over 10 days beginning on July 10, 2008, prior to flooding. Due to high regulation in this basin, the intra-annual flow has been extremely stable since the 1970s, and the runoff hydrograph during the sampling period was close to the average hydrograph in the post-dams periods (Zhang et al. 2010) (Figure 2). Plankton, including phytoplankton and zooplankton, and macroinvertebrates were selected as the main assessment indicators because both are widely available and convenient to sample. Replicate samples were collected at each site according to relevant published guidelines (EPAC, 1993; MWR 1998). Although fish are often employed as a bioindicator in river ecosystem health studies, the fish communities of the Huai River Basin are already under severe stress, and many have already become extinct or extremely rare due to serious pollution (Zhao et al., 2012). To avoid further diminishing fish stocks and difficulties with sampling from such a sparse community, more prevalent biota were chosen as biological indicators.

Phytoplankton were collected at approximately $10 \mathrm{~cm}$ below water surface using plastic polymethyl methacrylate (PMMA) water collection apparatus. The 1-L samples were stored in pre-cleaned bottles and preserved with $1.5 \%$ Lugol's iodine solution. After 24 hours, sufficient precipitation had occurred to decant the supernatant, leaving $30 \mathrm{ml}$ of concentrated phytoplankton. Numerical phytoplankton analysis was carried out using Utermohl's inverted plankton microscope according to literature (Sicko-Goad et al. 1977; Rott 1981). The phytoplankton abundance of each site (number of individuals/L) were estimated by averaging the sample aboundance of subsamples.

Zooplankton, including protozoa and rotifer, were collected within $5 \mathrm{~cm}$ of the surface in the middle of the river using PMMA bottles. Larger taxa, including cladocera 
1 and copepods, were collected using a No. 25 phytoplankton net (aperture size: 0.065 $\mathrm{mm})$. All zooplankton samples were stored in pre-cleaned bottles with 1.5\% Logul's solution. In the laboratory, each sample was deposited for 24 hours and concentrated, then split in a Folsom plankton splitter to subdivide to two subsamples. Cladocera and copepods were identified using the method described by Evans et al. (1982). The zooplankton abundance of each site (number of individuals/L) were estimated by averaging the sample aboundance of subsamples.

Most of these sites were distributed in the middle and lower reaches where the substratum predominantly consists of mud and sand. Benthic macroinvertebrate samples were collected from the riverbed by the improved Peterson grab sampler (outlet: 29 $\mathrm{cm} \times 19 \mathrm{~cm}$ ), washed through a $1 \mathrm{~mm}$ sieve and stored in plastic bags with $2 \mathrm{ml}$ of $75 \%$ ethyl alcohol. In the laboratory, macroinvertebrates were identified to genus level (number of individuals per $\mathrm{m}^{2}$ ).

Environmental data There are many physical and chemical factors that potentially influence river ecosystem health such as the watershed area, population density, distances down from sluices and dams, water quality, climate, land cover, edaphic factors, flow regimes and so on. For the Huai River Basin, forty-four environmental variables from six major independent categories (climate, land cover, edaphic factors, flow regimes, water projects and water quality) were chosen for statistical detection and population density, as an integrated and indirect factor, was ignored (Table 1). Climate factors likely provide energy and water for ecosystem growth and reproduction (Stenseth et al., 2002; Moisan et al., 2002). Land cover and edaphic factors may provide biogenic materials and substrate for organisms and form habitat (Mackay at al. 2003). Flow regime (including magnitude, frequency, duration and timing of particular flows and the variability of the overall flow regime), is a major physical determinant, and its variation could affect the energy and material transmission process and disturb the process of organism growth (Bunn and Arthington, 2002). Water quality includes nutrients and oxygen for organisms (Turak et al. 1999); a high concentration of nutrients could cause eutrophication and aquatic hypoxia, which inhibit organism growth. Furthermore, a high density of dams and sluices fragmented most rivers, directly disturbed natural flow regime characteristics and consequently affected river ecosystem health in the Huai River Basin. Thus, the influence of dams and sluices 
1 cannot be ignored (Zhang et al., 2010; 2012), and their impact is a long-term cumulative

process. For this reason, long-term series of regulated and unregulated runoff were needed to analyze the impact of water projects on flow regimes and their potential impact on river ecosystem health.

Climatic data were obtained at 10 weather stations from the China Meteorological Administration (http://cdc.cma.gov.cn/index.jsp). The values of climate variables were calculated by the area weighted average method. Land use and soil types were obtained from the Data Center for Resources and Environmental Sciences (http://www.resdc.cn/). Areas of land use and soil types were calculated by ArcGIS 10.0 software at each sub-basin that was controlled by the sample site. Hydrological data included monthly regulated discharges between 1961 and 2000, which were obtained from the Huai River Commission. Corresponding unregulated discharges were obtained from the output of the Zhang et al. (2010) hydrological model. The change of flow regimes between unregulated and regulated discharges was calculated for flow regime factors. The selected variables were magnitude, frequency, duration and timing of change in flow events, which influenced the ecological integrity of rivers both directly and indirectly (Poff et al. 1997). The values of hydrologic variables were calculated by programming using Compaq Visual Fortran 6.0 software according to Zhang et al. (2012). Seven water quality variables were selected according to national guidelines for surface water quality (EPAC 2002). Direct measurements or samples for lab analysis were taken at each site for each of these variables. However, it was very difficult to collect data on these six categories, especially flow regimes data, for all 71 sites. In addition, it was unfeasible to simulate runoff processes using hydrologic models in the reticular river networks downstream of the Huai River Basin; therefore, only the flow regimes at the upper and middle streams were modeled. Thus, 33 sites in the upper and middle regions of the Huai River Basin were selected to test the environmental factors. Their geographic features are shown in Table 2.

\section{River ecosystem health assessments}

Assessment bioindicators. Data on the ecosystem's biodiversity and macroinvertebrate tolerance to pollution were obtained from the literature and from the primary data collected in this study to assess ecosystem health status, including species 
1 diversity, richness, dominance and evenness. The Shannon-Weaver diversity index $(H)$, 2 which reflects species diversity in the river ecosystem, has been a popular and 3 well-developed index in the ecological literature (Shannon and Weaver 1949). The maximum value occurs when different species are uniform in abundance. Margalef's species richness index (D) reflects the number of different species in the river 6 ecosystem (Margalef 1958). Species richness is related to species diversity, but they are not the same thing; richness does not take proportional abundances into account and is therefore the actual count of species (Tuomisto 2010). If a large number of species are identified, the D value will also be high. Simpson's dominance index (S) reflects the dominance degree of species in the river ecosystem, which varies between zero and one (Simpson 1949). The smaller the value is, the more prevalent the dominant species are. Pielou's evenness index $(\mathrm{J})$ is a measurement of how evenly distributed the abundance is among extant species (Pielou 1959). The larger the value, the more uniformly the species are distributed. The Hilsenhoff biotic index (HB) reflects the tolerance of macroinvertebrate species to pollution, and also indirectly reflects the degree of river pollution. The larger the value, the more heavily the river was polluted. All of these calculations were performed using Microsoft Office Excel 2003 software.

- Shannon-Weaver diversity index $(\mathrm{H})$

$$
H=-\sum_{i=1}^{s}\left[\left(\frac{n_{i}}{N}\right) \ln \left(\frac{n_{i}}{N}\right)\right]
$$

- Margalef's species richness index (D)

$$
d=\frac{s-1}{\ln N}
$$

- Simpson's dominance index (S)

$$
\mathrm{S}=1-\sum_{i=1}^{3} \frac{n_{i}\left(n_{i}-1\right)}{N(N-1)}
$$

- Pielou's evenness index (J)

$$
J=\frac{H}{\ln s}
$$

- Hilsenhoff biotic index (HB)

$$
P T 2=\frac{\sum_{i=1}^{s}\left(n_{i} \cdot t_{i}\right)}{N}
$$


where $n_{i}$ is the individual number of the $i$ th species in the samples per liter (ind/L), $N$ is the total number of individuals in the samples ind/L, $s$ is the number of species in the sample, and $t_{i}$ is the tolerance value of the $i$ th macroinvertebrate species. The value of each species was gathered from the literature (Hilsenhoff 1987; Wang et al. 2004).

River ecosystem health standards. Currently, river ecosystem health standards are understudied in China (Liu and Liu 2009). In this study, the main hypothesis of "healthy ecosystems" was that species were abundant and diverse, but not dominant, and the macroinvertebrate species were less tolerant to water pollution. Based on past research experiences, long-term runoff data and environmental monitoring data in the Huai River Basin, river ecosystem health (IndH) was separated into five categories to maintain consistency with the five standard categories in the national environmental quality for surface water (EPAC 2002), according to the objective of this study (Table 3), as follows:

Morbid ( $\operatorname{IndH}=1$ ): Natural characteristics have been severely disturbed by human activities, and the number of biological organisms is low. Key ecosystem processes are not functioning, and the ecosystem is extremely unstable.

Unhealthy ( $I n d H=2$ ): Natural characteristics have been disturbed by human activities, and species composition and ecosystem structure have been drastically altered. Dominant species are prevalent. Ecosystem services are in decline. The stress of human activities has overwhelmed the ecosystem's capacity, resulting in instability.

Sub-healthy ( IndH=3): River characteristics are somewhat disturbed, and biodiversity and ecosystem structure have been changed to some extent. The pressure of human activities on the ecosystem has exceeded the ecosystem's capacity. However, the ecosystem still demonstrates the ability to recover.

Healthy ( $I n d H=4$ ): River characteristics are normal and biodiversity and ecosystem structure remain stable. The main ecosystem services are functioning, and the pressure of human activities is within the ecosystem's capacity.

Very healthy ( $\operatorname{Ind} H=5$ ): Human activities have had a negligible impact on river condition. Biological species are abundant and uniformly distributed. The ecosystem structure is stable, and its services are diverse. 
Integrated Assessment Model. River ecosystem health (IndH) was quantified in two steps. First, the four ecological indexes (H, D, S, and J) at each site were calculated by integrating each corresponding index of phytoplankton, zooplankton and benthic macroinvertebrates, and the values of PTI of benthic macroinvertebrates at each site were also calculated. A weighting algorithm was used to integrate the different indexes, thus,

$$
B I(\dot{E}) w_{1} I_{1}+w_{2} I_{2}+w_{3} I_{3}
$$

where $B I(i)$ is the integrated value of $\mathrm{H}, \mathrm{D}, \mathrm{S}, \mathrm{J}$ and $\mathrm{HB}$ indexes at site $i . I_{x}$ are the ecological index values of phytoplankton, zooplankton and benthic macroinvertebrates, and $w_{\mathrm{x}}$ is the weight applied to each index. The weights of these three aquatic organisms were determined based on their habits, representativeness, previous studies and sensitivity analysis. Benthic macroinvertebrates often assemble in certain reaches and were less affected by the variation of flow regimes. The community thus provides more information for chronically monitoring river ecosystem health (Dai and $\mathrm{Ni} 2008$; Masese et al. 2009; Fellows et al. 2006). Zooplankton and phytoplankton have a short life cycle and will quickly adapt to short-term impacts (Zhao et al. 2008). Species diversity and biomass of zooplankton and phytoplankton are widely used as ecological indictors for river ecosystem health assessment (Xu et al. 1999). Based on the Delphi method (Altschuld, 2003), the weights of these three aquatic organisms were determined by expert knowledge gained from long-term experience with river ecosystem health. Those experts included professional and technical personnel in the Huai River Water Resources Protection Bureau and water environment and ecology researchers in the Chinese Academy of Sciences. After comprehensive analysis of the opinions of these experts on indicator weights, the weights of three indicators, i.e., benthic macroinvertebrate $\left(w_{1}\right)$, zooplankton $\left(w_{2}\right)$ and phytoplankton $\left(w_{3}\right)$, were determined to be $0.50,0.25$, and 0.25 , respectively. When one biota component was missing in the data, the weighting values of the two remaining biota components were set as 0.50. A sensitivity analysis of the effect of weights was also conducted preliminary by setting three groups of weights: $0.50,0.25,0.25 ; 0.33,0.34,0.33$; and $0.50,0.30,0.20$, and contrasting the health status of these different weights groups.

Secondly, the state of the ecosystem health of each site was determined by comparing $B I(i)$ values with the standard values of these five categories. The multi-step 
grey correlation evaluation method was used in this step, which measured the geometric similarity between samples and a certain grade standard matrix according to the correlation degree. The weight value of each index was based on the samples, which overcame the limits of subjective weighting (Xia 1999). Thus, the five values of correlation degree were calculated. The higher the correlation degree, the closer the sample was to the corresponding standard category, and the ecosystem health category was confirmed. All of these steps were performed by the multi-step grey correlation evaluation system software (register number: 2006SRBJ2140) developed by Xia et al. (2006) issued by National Copyright Administration of China.

\section{Multivariate analyses}

There were 71 sites distributed in the whole Huai River Basin and 31 sites in the upper and middle regions. Thus, to overcome the lack of long-term monitoring, we analyzed the spatial variation of ecosystem health to detect influential factors. The surrounding environment and catchment of each site was quite distinct, with diverse climatic elements, flow regime characteristics, water quality, land cover, soil, etc. The nonparametric multivariate analysis was employed to examine multi-species responses in the river ecosystem. Firstly, the nonparametric Kruskal-Wallis test was applied to qualitatively detect the effects of watershed area, distances down from sluices and dams, water quality degree on the ecosystem health. If the p-value was less than or equal to the significance level, their effect on ecosystem would be significant. Secondly, distance-based redundancy analysis (db-RDA), which is a new multivariate technique for testing the significance of individual terms in a multifactorial analysis-of-variance model for multispecies response variables, was used to partition the variability in the data (Legendre and Anderson 1999; McArdle and Anderson 2001). All the environmental data and biological data were standardized by logarithm $(x+1)$ transformation because logarithmic data generally showed strong matrix correlations at the biological species, genus and family levels in the environmental data (Heino J. 2008). The resemblance between the samples and environmental factors were calculated by the semi-metric Bray-Curtis distance measure, and significant influential factors were selected step by step based on Akaike's Information Criterion (AIC) selection criterion. The significance level was set at 0.05 , and the relationship was considered to 
1 be statistically significant if the p-value was less than or equal to 0.05 . All of these

\section{Results and Discussions}

\section{Species composition and distribution} comprised only $3.4 \%$ of all taxa.

Phytoplankton A total of 58 phytoplankton taxa consisting of 39 genera were identified at 71 sites (Figure 3a). The most dominant divisions, in descending order, were Chlorophyta (17 genera), Cyanobacteria (12 genera), Bacillariophyta (six genera), Dinoflagellate (two genera) and Euglena (two genera). Cyanobacteria and Chlorophyta constituted $74.4 \%$ of all taxa and $99.8 \%$ of the total counted individuals (Figure 3a). The highest diversity was observed at Dawangmiao (14 taxa) in the Huiji River, which accounted for $24.1 \%$ of all taxa. The lowest diversity (2 taxa) was observed at Huaian and Nanzhao in the Huai River and Sanhezha in Hongze Lake, which together

Zooplankton A total of 104 taxa consisting of 74 genera were identified, including Rotifer (24 genera), Cladocera (11 genera), Copepoda (17 genera), Protozoans (11 genera), Nauplius (two genera) and others (nine nauplii) (Figure 3b). The dominant genera were Rotifer and Cladocera, which accounted for $65.1 \%$ of all genera and $88.1 \%$ of total individuals (Figure 3b). The highest number of taxa was observed at Yingshang in the Shaying River, which had 21 taxa and constituted $20.2 \%$ of all taxa, whereas the lowest number of taxa (only one) was observed at Hengpaitou in the Pi River, which only constituted one percent of all taxa. The highest abundance was $14528.33 \mathrm{ind} / \mathrm{L}$ observed at the Bozhou site in the Guo River, and the lowest abundance was at the Hengpaitou site in the Pi River, which had less than 1 ind/L.

Benthic macroinvertebrate Benthic macroinvertebrates were found at 59 investigated sites. Only 24 taxa were identified, including Gastropoda (10 genera), Lamellibranchiate (seven genera), Oligochaeta (three genera), Crustacea (two genera), Hirudinea (one genus) and Insecta (one genus) (Figure 3c). The predominant genera were Gastropoda and Oligochaeta, which constituted $54.2 \%$ of all genera and $86.4 \%$ of the total counted individuals (Figure 3c). The highest number of taxa (10) was observed at the Suqian site in the East Canal, which constituted $41.7 \%$ of all taxa, whereas the lowest number of taxa were observed at Huaibin, Nanzhao and Huainan in the Huai 
1 River, Jishu in the Dongyu River, Liangshan in the Zhuzhao River, Yanzhou and Linsu

\section{River ecosystem health conditions in the Huai River Basin}

At all 71 sites, predominant species were evident. There were only 39 genera of Phytoplankton, and Cyanobacteria and Chlorophyta were predominant, with relative densities of $94.4 \%$ and 5.4\%, respectively. Among the 63 genera of Zooplankton, Rotifer (44.0\%) and Cladocera (44.1\%) were the predominant genera. Moreover, there were only 24 genera of benthic macroinvertebrates, and Gastropoda (62.3\%) and Oligochaeta $(24.1 \%)$ were the most predominant. Thus, the whole ecosystem in the Huai River Basin was in a sub-healthy condition (Figure 4 and Table 4).

There were 31 sites in healthy condition, accounting for $44 \%$ of all sites. The healthy ecosystem sites were distributed in the lower reaches and the southern mountain streams. Possible explanations for their healthy conditions are large distances from dams and sluices, the maintenance of natural habitat niches and the low level of anthropogenic disturbance in the mountainous sites (See Figure 1). There were 21 sites over $20.0 \mathrm{~km}$ downstream from dams and sluices, and these sites accounted for $77 \%$ of the healthy sites. There were 36 sites in sub-healthy condition with fragile ecosystems, accounting for $51 \%$ of the total sites. All of these sites were in the upper reaches and in lakes. Thirty-nine percent (14/36) of the sites in the upper rivers were disturbed by river regulation, and $42 \%(15 / 36)$ of the sites were seriously polluted which were worse than Class V.

The other four sites were in unhealthy conditions and accounted for $5 \%$ of all sites. All of these sites were disturbed by intensive human activities. Pizhou and Liangshan are located in the Beijing-Hangzhou Grand Canal, which is one of busiest waterways in China (Figure 1). Thus, the incessant vehicular traffic and artificial channels have destroyed the river habitat. Moreover, water quality degrees at all of these four sites were worse than Class V, which means the rivers were polluted heavily. The water 
1 quality variables that exceeded the standards were total nitrogen (average values of 4.69 $\mathrm{mg} / \mathrm{L}$ and the standard of Class $\mathrm{V}: 2.00 \mathrm{mg} / \mathrm{L}$ ) and ammonia nitrogen (average values of $2.81 \mathrm{mg} / \mathrm{L}$ and the standard of Class V: $2.00 \mathrm{mg} / \mathrm{L}$ ) (Figure 4).

The sensitivity analysis of weights allocated to the phytoplankton, zooplankton and benthic macroinvertebrates was conducted, and the results revealed that $76 \%(54 / 71)$ and $73 \%(52 / 71)$ of the sites were in the same health category when the weights of the three organisms were changed from $0.25-0.25-0.50$ to $0.33-0.34-0.33$ and 0.20-0.30-0.50, respectively. Thus, changing the weights did not significantly alter the proportion of sites allocated to healthy, sub-healthy or unhealthy categories (Table 4). The weights of $0.25,0.25$ and 0.50 were chosen as a compromise between simplicity and representation of the theoretical contributions of each group to river ecosystem health.

\section{Factors influencing aquatic ecosystem health}

The proceeding analysis suggests that the factors that influence river ecosystem health are watershed area, distance downstream from dams or sluices, climate, hydrological regulation, pollution, soil properties, land use and human activities such as sand mining and commercial fishing.

The watershed area ranged from $580 \mathrm{~km}^{2}$ to $119,986 \mathrm{~km}^{2}$, and the watershed area of 30 of the 33 sites $(91 \%)$ was not greater than $40,000 \mathrm{~km}^{2}$. The ecosystems of most sites (26/33) were sub-healthy, with two sites categorized as healthy and four sites categorized as unhealthy, and the water quality degree was Class III at 10 sites, Class IV at seven sites and Class V or worse at 16 sites. Most unhealthy and sub-healthy sites (18/33) were located less than $50 \mathrm{~km}$ downstream of dams or sluices. Moreover, most unhealthy and sub-healthy sites (18/33) were located less than $50 \mathrm{~km}$ downstream of dams or sluices and the same as the polluted sites (12/33) with water quality degrees of Class IV or worse. By Kruskal-Wallis test, the effect of watershed size on both water quality degree and ecosystem health was not significant, but the effect of the distance down from dams or sluices was significant on ecosystem health, but not on water quality degree. Also the water quality affected on the ecosystem health significantly (Table 5).

Using multivariate analyses, similarity with the variation of phytoplankton, 
1 zooplankton, benthic macroinvertebrate samples as well as the whole ecosystem and the

2 factors passed the significant test are shown in Table 6 and the affected proportion was quantified.

Phytoplankton The solar radiation (SRD), the number of zero-flow months (ZERON), minimum temperature (MINT) and relative humidity (RHUM) have statistically significant relationships with phytoplankton. Together these factors accounted for $37.5 \%$ of the spatial variation of phytoplankton, and climate factors (SRD, MINT and RHUM) were the factors with the strongest influence. These climatic factors accounted for $29.3 \%$ of spatial variation, suggesting strong climatic control of the growth rate and condition of phytoplankton. Climatic factors were followed in importance by hydrologic factors (ZERON), which accounted for $8.2 \%$ of the spatial variation. These factors were often controlled by the regulation of dams and sluices and they controlled habitat form and the dynamics of nutrient exchange.

Zooplankton The SRD, area of paddy and grassland (PADDY and GRASS), predictability and seasonality of mean monthly runoff (PMMF and SMMF) and ammonia nitrogen $\left(\mathrm{NH}_{3}-\mathrm{N}\right)$ all have statistically significant relationships with zooplankton abundance. Together, these factors can explain $42.3 \%$ of the spatial variation in zooplankton levels. Like phytoplankton, climatic factors (such as SRD) were the factors with the most influence, accounting for $13.5 \%$ of variation. Changes in solar radiation likely drive the exchanges of heat, momentum and water that ultimately determine zooplankton growth, recruitment and migration patterns (Stenseth et al., 2002; Moisan et al., 2002). The second most influential factors, PADDY and GRASS, which accounted for $12.9 \%$ of variation, were land use variables, which provide substrate for the zooplankton. The third most influential group was hydrologic factors, PMMF and SMMF, which accounted for $10.6 \%$ of variation and affect the breeding, spawning and maturation processes of zooplankton. The final variable was water quality, $\mathrm{NH}_{3}-\mathrm{N}$, which accounted for $5.3 \%$ of variation and could affect aquatic nutrient levels and the growth rates of zooplankton.

Benthic macroinvertebrates Both the $\mathrm{NH}_{3}-\mathrm{N}$ and the 10-year average recurrence interval of flood (ARI10) variables have a statistically significant relationship with the spatial variation of benthic macroinvertebrates. These factors together explained $19.7 \%$ of the variation. The notable absence of climate as a significant factor is likely due to 
1 the insulating properties of the water column above the bottom-dwelling 2 macroinvertebrates. The amount of variation explained by water quality and hydrologic 3 factors was $12.8 \%$ and $6.9 \%$, respectively.

Ecosystem. Results showed that SRD, predictability of mean monthly runoff (PMMF), baseflow index (BI) and paddy soil (PADS) have statistically significant relationships with river ecosystem health. SRD, a climatic factor, was the variable with the most influence and accounted for $13.1 \%$ of the variation in river ecosystem health. SRD was followed by hydrologic factors (PMMF and BI together explained $11.4 \%$ of variation), which influence the breeding, spawning and maturation processes and control the provision of biologically useful habitats. Climate and hydrological factors were followed by soil (PADS), which explained 5\% of variation. Soil determines the availability of nutrients for ecosystem growth and decay processes.

\section{Conclusions}

River ecosystem health assessment is both an urgent and difficult requirement for integrated river basin management in China. Assessing ecosystem health is difficult primarily because of the paucity of suitable monitoring programs. This attempt at assessing river ecosystem health in the Huai River Basin showed two main results:

(1) The Huai River ecosystem is in a sub-healthy and fragile condition at present. Of the 71 sites investigated, $43.7 \%$ were categorized as healthy, mostly in the lower reaches of the Huai River and the East Canal, the southern mountain streams and the Shaying River. Just over half $(50.7 \%)$ of the sites were categorized as sub-healthy, most of which were in the upper reaches of the Hongru and Yishusi Rivers, Nansi Lake and Hongze Lake. The other sites (5.6\% of all sites) were categorized as unhealthy, and these were Yingshang in the Shaying River, Dawangmiao in the Guo River and Pizhou and Liangshan in the East Canal. The assessment results were reasonable, as they were close to the results of Zhao et al. (2008) and the national environment state bulletin in 2010 (EPAC 2010). The bioindicator assessment framework would promote the use of biological indicators in conventional water monitoring plans in China, and accelerate the transition of water management from water quantity management to water quality and even river health management.

(2) The key factors influencing river ecosystem health were detected by 
1 multivariate analysis. Climatic factors were identified as the factors with the most

influence on ecosystem health. The mechanism by which climate drives exchanges of heat, momentum and water that ultimately determine ecological growth, recruitment and migration patterns is well understood (Stenseth et al. 2002; Moisan et al. 2002). The second most influential group was hydrologic factors, which are known to directly affect the formation of habitat and nutrient exchange, which are the lifecycle processes of freshwater organism biodiversity (Poff et al. 1997; Webb et al. 2010). The third most influential groups were land use, water quality and edaphic factors, which determine the provision of organic matter and nutrients for the formation, reproduction and growth of riverine organisms and affect the biodiversity of aquatic biological communities (Timchenko et al. 2000). Also, the effect of the distance down from dams or sluices was significant on ecosystem health. To improve river ecosystem health in the Huai River Basin, the simple economic-oriented regulation of dams and sluices, as well as water quality control, should be modified with ecological outcomes as a priority, such as integrated "water quantity - quality - ecology" regulation. Additionally, the threat of climate change on river ecosystem should be necessarily taken into account in integrated river basin management.

As an initial exploration on the Huai River Basin ecosystem instead of the tranditional water quality assessment techniques, we set out to analyze the macroscopic distribution of river ecosystem health in the different flow regime periods and the main influencing factors. Using only one time sample is insufficient and contains many uncertainties affected by sampling methods, climate, flow regimes and the regulation of dams or sluices. Therefore, it was difficult to interpret all variations of the ecosystem. However, we were able to compare the spatial variation of the ecosystem health of all 71 sites, detect all of the potential influential factors based on their surrounding environment and interpret $19.7 \%-42.3 \%$ of variation in the ecosystem. The results were still helpful and significant considering that our capacity is inadequate for predicting the effects of human activity on freshwater ecosystems and given the complex mechanisms of human activity on ecosystems all over the world, not just in China. Further research should include additional biological indictors (such as fish and periphyton), assessment standards, weighting determination, sample site selection, the effect of dams and sluices, climate and long-term monitoring. 


\section{Acknowledgements}

3 This study was supported by Huai River Project for Major Science and Technology

4 Program for Water Pollution Control and Treatment (No.2014ZX07204-006) and

5 Natural Science Foundation of China (No. 41271005). Thanks to Cheng Xushui, Zhou

6 Jiebing, Zhang Yanzai from Huai River Water Resources Protection Bureau, Dr. Zhang

7 Liang, Dr. Liu Xin from Institute of Geographic Sciences and Natural Resources

8 Research, Chinese Academy of Sciences and Prof. Liu Min, Dr. Lin Xiao from East

9 China Normal University for their contribution for samples collection and Dr. Rob Rolls

10 from Griffith University, Australia for data analysis. Thanks to Elsevier languages

11 editors, Stephen Fujiwara in University of Technology Sydney, Kass Hingee in the

12 CSIRO Mathematical and Information Sciences, Australia and Dr Xiaoyan Zhai in

Wuhan University, China for their help to revise the paper. Thanks also to the anonymous referees for their valuable comments and suggestions, which significantly improved the quality of the paper.

\section{References}

Arthington, A.H.,Naiman, R.J., Mcclain, M.E., Nilsson, C.(2010). Preserving the biodiversity and ecological services of rivers: new challenges and research opportunities. Freshwater Biol. 55, 1-16.

Altschuld, J. W. (2003). Delphi technique. Lecture, Applied evaluation design. The Ohio State University.

Bunn,S.E. and Arthington, A.H. (2002). Basic principles and ecological consequences of altered flow regimes for aquatic biodiversity. Environmental Management 30(4): 492-507.

Cai, L.Z., Ma, L., Gao, Y., Zheng, T.L., Lin, P. (2002). Analysis on Assessing Criterion for Polluted Situation Using Species Diversity Index of Marine Macrofauna. $J$. Xiamen University (Natural Science), 41(5):641-646.

Chen, H., Shi, X.L., Tan, X.L. et al., (2007). Changes of Protozoao Community Diversity in the Swampy Water Area in Hangzhou China. Chin. J. Ecol. 26(10):1549-1554. (In Chinese).

Downes, B.J. (2010). Back to the future: little-used tools and principles of scientific 

inference can help disentangle effects
ecosystems. Freshwater Biol. 55 (1): 60-79.

Environmental Protection Administration of China (EPAC), (1993). Aquatic biological monitoring manual. Nanjing: Southeast University Press. (In Chinese).

Environmental Protection Administration of China (EPAC), (2010).The National Environment State Bulletin in 2010. (In Chinese).

Environmental Protection Administration of China (EPAC), (2002). GB 3838-2002 Environmental quality standards for surface water. Beijing: China Environmental Science Press. (In Chinese).

Evans, M. S., Sell, D. W. \& Page, D., (1982). Zooplankton studies in 1977 and 1978 at the Donald C. Cook Nuclear Power Plant: Comparisons of Preoperational (1971-1974) and Operational (1975-1979) Population Characteristics.Univ. Mich . Great Lakes Res . Div . Spec . Rept . 89 . 235 pp .

Fairweather, P.G.. (1999). State of environmental indicators of river health: exploring the metaphor. Freshwater Biol.41, 221-234.

Fellows, C.S., Clapcott, J.E., Udy, J.W., Bunn, S.E., Harch, B.D., Smith, M.J., Davies, P.M. (2006) Benthic Metabolism as an Indicator of Stream Ecosystem Health. Hydrobiologia, 572 (1):71-87.

Heino, J. (2008). Influence of taxonomic resolution and data transformation on biotic matrix concordance and assemblage-environment relationships in stream macroinvertebrates. Boreal Env. Res. 13:359-369.

Hilsenhoff, W.L., (1987). An improved biotic index of organic stream pollution. Great Lakes Entomologist. 20: 31-39.

Ji,Y.Y., Feng, S.D., Han, Y.Y., Wang, C.Y. (2009). The diatom biology index appraisal in pond-wetland combined eco-system. J. Shenyang Normal University(Natural Science) 27(1):114-118. (In Chinese)

Karr, J.R. (1999). Defining and measuring river health. Freshwater Biol., 41: 221-234.

Karr, J. R., (1981). Assessment of biotic integrity using fish communities. Fisheries 6 (6): 21-27.

Karr, J.R. (1999). Defining and measuring river health. Freshwater Biol., 41: 221-234.

Kennard, M.J., Pusey, B.J., Mackay, S.J., Olden, J.D. \& Marsh, N. (2010). Quantifying uncertainty in estimation of hydrologic metrics for ecohydrological studies. River 
Research and Applications. 26: 137-156

Kong, F.X. (2000). Environmental Ecology. Beijing: Higher Education Press, China 162-163. (In Chinese)

Ladson, A.R., White, L.J., Doolan, J.A., et al., (1999). Development and testing of an index of steam condition for waterway management in Australia. Freshwater Biol. 41:453-468.

Legendre, P. and Anderson, M.J.(1999).Distance-based redundancy analysis: testing multispecies responses in mutifactorial ecological experiments. Ecol. Monogr. 69(1):1-24.

Liu, C.M. and Liu, X.Y. (2009). Healthy river and its indication, criteria and standards. $J$. Geogr. Sci. 19: 3-11.

Mackay, S.J., Arthington, A.H., Kennard, M.J. and Pusey, B.J. (2003). Spatial variation in the distribution and abundance of submersed macrophytes in an Australian subtropical river. Aquat. Bot. 77:169-186.

Margalef, R.,(1958). Information theory in ecology. General Systematics.3:498-510.

Masese, F.O., Raburu, P.O. and Muchiri, M.A. (2009). Preliminary benthic macroinvertebrate index of biotic integrity (B-IBI) for monitoring the Moiben River, Lake Victoria Basin, Kenya. African J. Aquat. Sci. 34(1): 1-14.

McArdle, B.H. and Anderson, M.J. (2001).Fitting multivariate models to community data: a comment on distance-based redundancy analysis. Ecology, 82(1): 290-297.

Meng, W., Zhang, N., Zhang, Y., Zheng, B.H. (2009). Integrated assessment of river health based on water quality, aquatic life and physical habitat. J. Environ. Sci.-China 21:1017-1027.

Moisan, J.R., Moisan, T.A., Abbott, M.R.(2002). Modelling the effect of temperature on the maximum growth rates of phytoplankton populations Ecol. Model. 153 :197-215.

Norris, R.H. and Thoms, M.C., (1999). What is River Health. Freshwater Biol. 41: 197-209.

Petersen, R.C.,(1992). The RCE: a riparian, channel, and environmental inventory for small streams in the agriculture landscape. Freshwater Biol. 27:295-306.

Pielou, E.C.,(1959). The use of point to plant distances in the study of the pattern of plant distribution. J. Ecol. 47:607-613. 
1 Poff, N.L., Allan, J.D., Bain, M.B., Karr, J.R., Prestegaard, K.L., Richter, B.D., Sparks, R.E., Stromberg, J.C. (1997). The natural flow regime: a paradigm for river conservation and restoration. Bioscience 47: 769-784.

Rapport, D.J., Costanza, R., Michael,A.J.,(1998). Assessing Ecosystem Health. Trends Ecol Evol. 13: 397-402.

Reynoldson, T. B., Norris, R. H., Resh, V. H., Day, K. E. and Rosenberg, D.M., (1997). The reference condition: a comparison of multimetric and multivariate approaches to assess water-quality impairment using benthic macroinvertebrates. J. N. Am. Benthol. Soc. 16: 833-852.

Rott, E. (1981). Some results from phytoplankton counting intercalibrations. Aquat. Sci. 43: $34-62$

Shannon, C. E., and Weaver, W.,(1949). The Mathematical Theory of Communication, Univ. of Illinois Press, Urbana.

Sicko-Goad L, Stoermer E, Ladewski B. (1977). A morphometric method for correcting phytoplankton cell volume estimates. Protoplasma 93: 147-163

Simpson, E.H. (1949). Measurement of diversity. Nature.163:688.

Simpson, J.C. and Norris, R.H.,(2000). Biological assessment of river quality: development of AUSRIVAS models and outputs. In Wright, J. F., D. W. Sutcliffe \& M. T. Furse (eds), Assessing the Biological Quality of Fresh Waters: RIVPACS and other techniques. Freshwat. Biol. Ass. Ambleside, U.K.: 125-142.

Stenseth, N.C., Mysterud, A. Ottersen, G., Hurrell, J.W., Chan, K.S., Lima, M. (2002). Ecological Effects of Climate Fluctuations. Science, 297: 1292- 1296.

Timchenko, V., Oksiyuk, O., Gore, J. (2000) A model for ecosystem state and water quality management in the Dnieper River delta. Ecol. Eng. 16:119-125.

Tuomisto, H. (2010). A consistent terminology for quantifying species diversity? Yes, it does exist. Oecologia 4: 853-860.

Turak, E., Flack, L.K., Norris, R.H., Simpson, J. and Waddell, N.(1999). Assessment of river condition at a large spatial scale using predictive models. Freshwater Biol. 41:283-298.

Water Resources Ministry of China (MWR) (1998). Regulation for Water Environmental Monitoring(SL219-98). Beijing:China Water Power Press.(In Chinese) 
1 Wang B.X. and Yang L.F. (2004). A study on tolerance values of benthic macroinvertebrate taxa in eastern China. Acta Ecologica Sinica, 24(1):2768-2775. (In Chinese)

Webb, J.A., Stewardson, M.J. Koster, W.M. (2010). Detecting ecological responses to flow variation using Bayesian hierarchical models. Freshwater Biol. 55, 108-126.

World Wide Fund for Nature and World Resources Institute (WWF and WRI) (2004) River at risk: Dams and the future of freshwater ecosystems. Panda House, Weyside Park Godalming, Surrey GU7 1XR.

Wright, J. F., Sutcliffe, D.W., Furse, M.T. (2000). Assessing the Biological Quality of Fresh Waters: RIVPACS and Other Techniques. Ambleside: The Freshwater Biological Association.1-24.

Xia J.,(1999). Regional water environment and ecological environment quality assessment: theory and application of multi-relation evaluation. Wuhan: Wuhan University of Hydraulic and Electrical Engineering Press. (In Chinese)

Xia J., Zhang Y.Y., Zhan C.S., Ye A.Z.,(2011). Water Quality Management in China:The Case of the Huai River Basin. Int J Water Resour D 27(1) :167-180.

Xu, F.L., Jørgensen, S.E., Tao, S. (1999). Ecological indicators for assessing freshwater ecosystem health. Ecol. Model. 116:77-106.

Ye, S.F., Liu,X., Ding,D.W. (2007). Ecosystem health assessment of the Changjiang River Estuary: indicator system and its primarily assessment. Acta Oceanol. Sci. 29 (4):128-136. (In Chinese)

Zhang,Y.Y., Arthington, A.H., Bunn, S.E., Mackay, S., Xia, J., Kennard, M.(2012). Classification of flow regimes for environmental flow assessment in regulated rivers: the Huai River Basin, China. River Res Appl 28: 989-1005.

Zhang,Y.Y., Xia,J., Liang,T., Shao,Q.X. (2010). Impact of water projects on River Flow Regimes and Water Quality in Huai River Basin. Water Resour Manag 24:889-908. Zhao, C.S., Xia, J.,Wang, G.S., Yan, W.J., Liu, M., Zhang, H.T., Liu, Y., Sun, C.L.(2008). Evaluation and analysis on aquatic ecology and environmental quality of Huai River basin. Chin. J. Environ. Eng. 2(12):1698-1704. (In Chinese).

Zhao, C.S., Liu, C.M., Xia, J., Zhang, Y.Y., Yu, Q., Derek, E.(2012). Recognition of key regions for restoration of phytoplankton communities in the Huai River basin, China. J. Hydrol. 420-421:292-300. 
1 Table1 The selected environmental variables to test the responses in river ecosystem

\begin{tabular}{|c|c|c|c|}
\hline Categories & Variables & Unit & Abbreviation \\
\hline \multirow{7}{*}{ Climate } & Precipitation & $\mathrm{mm}$ & PCP \\
\hline & Potential evaportranspiration & $\mathrm{mm}$ & PET \\
\hline & Maximum temperature & ${ }^{\circ} \mathrm{C}$ & MAXT \\
\hline & Minimum temperature & ${ }^{\circ} \mathrm{C}$ & MINT \\
\hline & Relative humidity & $\%$ & RHUM \\
\hline & Solar radiation & $\mathrm{J} / \mathrm{m}^{2}$ & SRD \\
\hline & Wind speed & $\mathrm{m} / \mathrm{s}$ & WSP \\
\hline \multirow{14}{*}{ Hydrology } & Mean monthly runoff & $\mathrm{m}^{3} / \mathrm{s} / \mathrm{km}^{2}$ & MMF \\
\hline & CV monthly flow & none & CVMMF \\
\hline & Baseflow index & none & $\mathrm{BI}$ \\
\hline & Low flow discharge $\left(90^{\text {th }}\right.$ percentile $)$ & none & \begin{tabular}{|l|l} 
LOW90 \\
\end{tabular} \\
\hline & High flow discharge $\left(>10^{\text {th }}\right.$ percentile) & none & HIG10 \\
\hline & 10-year Average Recurrence Interval of flood & none & ARI10 \\
\hline & Low flow spell count $\left(<90^{\text {th }}\right.$ percentile $)$ & none & LOWC90 \\
\hline & High flow spell count $\left(>10^{\text {th }}\right.$ percentile $)$ & none & HIGC10 \\
\hline & Low flow spell duration $\left(<90^{\text {th }}\right.$ percentile $)$ & none & LOWS90 \\
\hline & High flow spell duration $\left(>10^{\text {th }}\right.$ percentile $)$ & none & HIGS10 \\
\hline & Number of zero-flow month & none & ZERON \\
\hline & Predictability of MMF & none & PMMF \\
\hline & Constancy of MMF & none & CMMF \\
\hline & Seasonality of MMF & none & SMMF \\
\hline \multirow{5}{*}{$\begin{array}{l}\text { Water } \\
\text { quality }\end{array}$} & Potential of Hydrogen & none & $\mathrm{PH}$ \\
\hline & Ammonia nitrogen & $\mathrm{mg} / \mathrm{L}$ & $\mathrm{NH}_{3}-\mathrm{N}$ \\
\hline & Permanganate index & $\mathrm{mg} / \mathrm{L}$ & $\mathrm{COD}_{\mathrm{Mn}}$ \\
\hline & Total phosphorus & $\mathrm{mg} / \mathrm{L}$ & $\mathrm{TP}$ \\
\hline & Total nitrogen & $\mathrm{mg} / \mathrm{L}$ & TN \\
\hline \multirow{6}{*}{ Land use } & Dry farmland & $\mathrm{km}^{2}$ & DFL \\
\hline & Urban & $\mathrm{km}^{2}$ & URBAN \\
\hline & Paddy & $\mathrm{km}^{2}$ & PADDY \\
\hline & Forest & $\mathrm{km}^{2}$ & FOREST \\
\hline & Grassland & $\mathrm{km}^{2}$ & GRASS \\
\hline & Water & $\mathrm{km}^{2}$ & WATER \\
\hline \multirow{12}{*}{ Soil } & Cinnamon soil & $\mathrm{km}^{2}$ & CINNS \\
\hline & Alluvial soil & $\mathrm{km}^{2}$ & ALLUS \\
\hline & Urban soil & $\mathrm{km}^{2}$ & URBAS \\
\hline & Aeolian sandy soil & $\mathrm{km}^{2}$ & AEOS \\
\hline & Back soil & $\mathrm{km}^{2}$ & BLACKS \\
\hline & Brown soil & $\mathrm{km}^{2}$ & BROWNS \\
\hline & Loessal soil & $\mathrm{km}^{2}$ & LOES \\
\hline & Skeleton soil & $\mathrm{km}^{2}$ & SKELS \\
\hline & Paddy soil & $\mathrm{km}^{2}$ & PADS \\
\hline & Lake soil & $\mathrm{km}^{2}$ & LAKES \\
\hline & Chisley soil & $\mathrm{km}^{2}$ & CHISLS \\
\hline & Skeletol soil & $\mathrm{km}^{2}$ & SKELTS \\
\hline
\end{tabular}


1 Table 2 The geographic features of selected sites and their controlled catchments

\begin{tabular}{|c|c|c|c|c|c|}
\hline Site name & $\begin{array}{l}\text { Elevation } \\
\quad(\mathrm{m})\end{array}$ & $\begin{array}{l}\text { Distance down } \\
\text { from dams or } \\
\text { sluices }(\mathrm{km})\end{array}$ & $\begin{array}{c}\text { Water } \\
\text { Temperature } \\
\left({ }^{\circ} \mathrm{C}\right)\end{array}$ & $\begin{array}{c}\text { Watershed } \\
\text { area } \\
\left(\mathrm{km}^{2}\right)\end{array}$ & Main land use and its proportion \\
\hline Minggang & 60 & 53.76 & 30.70 & 3007 & Dry farm $(47 \%)$ and Forest $(52 \%)$ \\
\hline Xixian & 59 & 68.07 & 30.60 & 9651 & Dry farm $(40 \%)$ and Forest $(41 \%)$ \\
\hline Huaibing & 55 & $>200$ & 28.70 & 16005 & Dry farm $(40 \%)$ and Forest $(41 \%)$ \\
\hline Nanzhao & 31 & $>200$ & 28.20 & 30136 & Dry farm $(65 \%)$ and Forest $(18 \%)$ \\
\hline Lutaizi & 28 & $>200$ & 28.70 & 89762 & Dry farm(66\%) and Paddy (15\%) \\
\hline Huainan & 45 & 39.83 & 28.70 & 89762 & Dry farm $(66 \%)$ and Paddy $(16 \%)$ \\
\hline Bengbu & 47 & $>200$ & 29.80 & 119986 & Dry farm $(70 \%)$ and Paddy $(16 \%)$ \\
\hline Wugouying & 69 & 18.60 & 30.00 & 786 & Dry farm $(47 \%)$ and Forest $(59 \%)$ \\
\hline Yuhuangmiao & 93 & 15.86 & 31.00 & 751 & Dry farm( $(76 \%)$ and Forest $(24 \%)$ \\
\hline Runan & 67 & 28.48 & 30.30 & 4405 & Dry farm $(80 \%)$ \\
\hline Bantai & 58 & 118.11 & 29.90 & 11116 & Dry farm $(90 \%)$ \\
\hline Pingdingshan & 84 & 25.43 & 33.00 & 2680 & Dry farm $(57 \%)$ and Forest $(43 \%)$ \\
\hline Luohe & 71 & 40.17 & 30.00 & 12057 & Dry farm $(74 \%)$ and Forest $(25 \%)$ \\
\hline Huaxing & 90 & 46.37 & 29.60 & 5200 & Dry farm( $(71 \%)$ and Forest $(29 \%)$ \\
\hline Huangqiao & 69 & 99.06 & 32.30 & 7022 & Dry farm(96\%) \\
\hline Zhoukou & 66 & 2.04 & 31.00 & 19443 & Dry farm $(83 \%)$ \\
\hline Jieshou & 66 & 34.13 & 29.80 & 28756 & Dry farm $(87 \%)$ \\
\hline Fuyang & 16 & 101.70 & 30.00 & 38294 & Dry farm $(90 \%)$ \\
\hline Yingshang & 16 & 75.14 & 30.20 & 39965 & Dry farm(91\%) \\
\hline Fugou & 71 & 0.00 & 29.80 & 5745 & Dry farm(96\%) \\
\hline Zhoukou & 43 & 0.54 & 28.40 & 7022 & Dry farm(96\%) \\
\hline Taikang & 31 & 19.78 & 29.90 & 580 & Dry farm $(100 \%)$ \\
\hline Bozhou & 37 & 25.75 & 28.90 & 10457 & Dry farm $(100 \%)$ \\
\hline Mengcheng & 49 & 50.25 & 29.60 & 13641 & Dry farm $(100 \%)$ \\
\hline Huaiyuan & 28 & 85.35 & 30.60 & 14153 & Dry farm $(100 \%)$ \\
\hline Dawangmiao & 60 & 161.30 & 28.90 & 3089 & Dry farm $(100 \%)$ \\
\hline Zhangdian & 37 & 65.49 & 28.90 & 1314 & Dry farm $(100 \%)$ \\
\hline Xinyang & 101 & 5.47 & 29.20 & 1062 & Forest $(100 \%)$ \\
\hline Hengpaitou & 66 & 41.79 & 26.70 & 4234 & Forest $(68 \%)$ and Grassland $(28 \%)$ \\
\hline Matou & 52 & 48.88 & 30.00 & 5405 & Forest $(59 \%)$ and Grassland $(25 \%)$ \\
\hline Zhengyang & 22 & 101.13 & 31.50 & 6736 & Forest (42\%) and Paddy(34\%) \\
\hline Yeji & 68 & 30.10 & 29.80 & 1913 & Forest $(46 \%)$ and Grassland $(33 \%)$ \\
\hline Shangsi Bridge & 68 & 30.75 & 30.30 & 803 & Forest $(80 \%)$ \\
\hline
\end{tabular}

2 
1 Table 3 The standard values of different indices corresponding to the different river 2 ecosystem healthy degrees

\begin{tabular}{|c|c|c|c|c|c|c|}
\hline $\begin{array}{l}\text { Healthy Degree } \\
\text { Index }\end{array}$ & Morbid & Unhealthy & Sub-healthy & Healthy & High-Healthy & References \\
\hline $\mathrm{H}$ (river) & 0 & $0-1$ & $1-2$ & $2-3$ & $>3$ & \multirow{2}{*}{ Kong et al. 2000} \\
\hline H(lake) & 0 & $0-0.5$ & $0.5-1.5$ & $1.5-2.5$ & $>2.5$ & \\
\hline D & $0-1$ & $1-2$ & $2-3$ & $3-6$ & $>6$ & $\begin{array}{l}\text { Cai et al. 2002; } \\
\text { Chen et al. } 2007\end{array}$ \\
\hline S & $0.0-0.2$ & $0.2-0.4$ & $0.4-0.6$ & $0.6-0.8$ & $0.8-1.0$ & $\begin{array}{l}\text { Cai et al. 2002; Ji } \\
\text { et al. } 2007 .\end{array}$ \\
\hline $\mathrm{J}$ & $0.0-0.2$ & $0.2-0.4$ & $0.4-0.6$ & $0.6-0.8$ & $0.8-1.0$ & $\begin{array}{l}\text { Cai et al. } 2002 ; \\
\text { Zhao et al. } 2008\end{array}$ \\
\hline $\mathrm{HB}$ & $>8.8$ & $7.7-8.8$ & $6.6-7.7$ & $5.5-6.6$ & $<5.5$ & $\begin{array}{c}\text { Hilsenhoff } \\
\text { 1987;Wang et } \\
\text { al.,2004 }\end{array}$ \\
\hline IndH & 1 & 2 & 3 & 4 & 5 & Ye et al. 2007 \\
\hline
\end{tabular}

3 
1 Table 4 The values of five indices of the 71 monitoring sites in the Huai River Basin

\begin{tabular}{|c|c|c|c|c|c|c|c|c|c|c|}
\hline ID & River Name & Site name & $\mathrm{H}$ & $\mathrm{D}$ & $\mathrm{S}$ & $\mathrm{J}$ & $\mathrm{HB}$ & IndH & $\overline{\operatorname{IndH}(1)}$ & $\operatorname{IndH(2)}$ \\
\hline 1 & \multirow{11}{*}{ Huai River } & Minggang & 0.83 & 0.71 & 0.71 & 0.52 & - & 3 & 3 & 3 \\
\hline 2 & & Xixian & 0.69 & 0.62 & 0.35 & 0.51 & 6.35 & 4 & 4 & 4 \\
\hline 3 & & Huaibin & 0.95 & 1.18 & 0.52 & 0.75 & 5.96 & 3 & 4 & 4 \\
\hline 4 & & Nanzhao & 0.75 & 0.73 & 0.38 & 0.55 & 5.96 & 3 & 4 & 4 \\
\hline 5 & & Lutaizi & 0.8 & 0.64 & 0.56 & 0.66 & 5.96 & 4 & 4 & 4 \\
\hline 6 & & Huainan & 0.83 & 0.92 & 0.44 & 0.54 & 5.96 & 3 & 4 & 4 \\
\hline 7 & & Bengbu & 0.88 & 1.45 & 0.51 & 0.53 & 5.96 & 4 & 4 & 4 \\
\hline 8 & & Linhuaiguan & 0.69 & 0.55 & 0.45 & 0.74 & 5.98 & 4 & 4 & 4 \\
\hline 9 & & Wuhe & 0.71 & 0.68 & 0.41 & 0.69 & 6 & 4 & 4 & 4 \\
\hline 10 & & Xuyi & 0.92 & 0.8 & 0.74 & 0.71 & - & 3 & 3 & 3 \\
\hline 11 & & Jinhu & 0.5 & 0.36 & 0.64 & 0.49 & 8.59 & 3 & 3 & 3 \\
\hline 12 & \multirow{4}{*}{ Hongru River } & Wugouying & 0.43 & 0.12 & 0.5 & 0.56 & 7.96 & 3 & 3 & 3 \\
\hline 13 & & Yuhuangmiao & 0.63 & -1.21 & 0.57 & 0.91 & 7.48 & 3 & 3 & 4 \\
\hline 14 & & Runan & 1.43 & 0.96 & 0.83 & 0.92 & 8.1 & 4 & 3 & 4 \\
\hline 15 & & Bantai & 1 & 0.54 & 0.59 & 0.74 & 6.1 & 4 & 4 & 4 \\
\hline 16 & \multirow{8}{*}{ Shaying River } & Pingdingshan & 0.87 & 0.68 & 0.43 & 0.54 & 5.96 & 4 & 4 & 4 \\
\hline 17 & & Luohe & 0.45 & 0.49 & 0.24 & 0.41 & 6.21 & 3 & 4 & 4 \\
\hline 18 & & Huaxing & 0.61 & 0.62 & 0.33 & 0.59 & 5.98 & 4 & 4 & 4 \\
\hline 19 & & Huangqiao & 0.74 & 0.39 & 0.42 & 0.64 & 6.54 & 4 & 4 & 4 \\
\hline 20 & & Zhoukou & 0.68 & 0.43 & 0.4 & 0.58 & 6.53 & 4 & 4 & 4 \\
\hline 21 & & Jieshou & 0.6 & 0.32 & 0.4 & 0.71 & 6.03 & 4 & 4 & 4 \\
\hline 22 & & Fuyang & 0.41 & 0.3 & 0.24 & 0.35 & 5.96 & 4 & 4 & 4 \\
\hline 23 & & Yingshang & 0.41 & 0.28 & 0.61 & 0.27 & - & 2 & 3 & 3 \\
\hline 24 & \multirow{2}{*}{ Jialu River } & Fugou & 0.36 & 0.17 & 0.49 & 0.53 & 9.09 & 3 & 3 & 3 \\
\hline 25 & & Zhoukou & 0.66 & 0.44 & 0.75 & 0.63 & 9 & 3 & 3 & 3 \\
\hline 26 & \multirow{6}{*}{ Guo River } & Taikang & 0.19 & 0.36 & 0.09 & 0.17 & 5.96 & 3 & 4 & 4 \\
\hline 27 & & Bozhou & 0.28 & 0.19 & 0.32 & 0.31 & 6.14 & 3 & 3 & 3 \\
\hline 28 & & Mengcheng & 0.89 & 0.61 & 0.43 & 0.54 & 5.96 & 4 & 4 & 4 \\
\hline 29 & & Huaiyuan & 0.22 & 0.31 & 0.1 & 0.24 & 5.97 & 4 & 4 & 4 \\
\hline 30 & & Dawangmiao & 0.73 & 0.5 & 0.7 & 0.49 & - & 2 & 3 & 3 \\
\hline 31 & & Zhangdian & 0.66 & 0.57 & 0.31 & 0.39 & 5.96 & 4 & 4 & 4 \\
\hline 32 & \multirow{3}{*}{ Hui River } & Guzheng & 0.52 & 0.25 & 0.3 & 0.55 & 5.98 & 4 & 4 & 4 \\
\hline 33 & & Yongcheng & 0.38 & 0.34 & 0.17 & 0.25 & 5.96 & 4 & 4 & 4 \\
\hline 34 & & Sixian & 0.33 & 0.23 & 0.17 & 0.24 & 5.98 & 4 & 4 & 4 \\
\hline 35 & \multirow{6}{*}{ Pi River } & Xinyang & 0.62 & 0.24 & 0.84 & 0.71 & - & 3 & 3 & 3 \\
\hline 36 & & Hengpaitou & 0.67 & 0.38 & 0.17 & 0.61 & - & 3 & 3 & 3 \\
\hline 37 & & Matou & 0.88 & 3.01 & 0.49 & 0.68 & 5.96 & 3 & 4 & 4 \\
\hline 38 & & Zhengyang & 0.93 & 1.09 & 0.49 & 0.61 & 5.96 & 3 & 4 & 4 \\
\hline 39 & & Yeji & 0.38 & 0.37 & 0.21 & 0.47 & 6.06 & 4 & 4 & 4 \\
\hline 40 & & Shangsi Bridge & 0.53 & 0.14 & 0.35 & 0.65 & 6.06 & 4 & 4 & 4 \\
\hline 41 & Dongyu River & Jishu & 0.52 & 0.71 & 0.29 & 0.43 & 5.96 & 3 & 4 & 4 \\
\hline 42 & Wanfu River & Sunzhuang & 0.76 & 0.76 & 0.74 & 0.56 & 8.95 & 3 & 3 & 3 \\
\hline 43 & Zhuzhao River & Liangshan & 0.44 & 0.28 & 0.25 & 0.4 & 5.96 & 3 & 4 & 4 \\
\hline 44 & \multirow{8}{*}{ Yishusi River } & Yanzhou & 0.49 & 0.5 & 0.29 & 0.45 & 5.96 & 3 & 4 & 4 \\
\hline 45 & & Yishui & 0.6 & 0.26 & 0.35 & 0.67 & 5.99 & 4 & 4 & 4 \\
\hline 46 & & Yinan & 0.52 & 0.63 & 0.66 & 0.45 & - & 3 & 3 & 3 \\
\hline 47 & & Linyi & 0.59 & 0.4 & 0.68 & 0.64 & - & 3 & 3 & 3 \\
\hline 48 & & Gangshang & 0.7 & 0.39 & 0.44 & 0.76 & 6.01 & 4 & 4 & 4 \\
\hline 49 & & Juxian & 0.8 & 0.9 & 0.42 & 0.64 & 7.92 & 3 & 3 & 3 \\
\hline 50 & & Linsu & 0.71 & 2.53 & 0.4 & 0.55 & 5.96 & 3 & 4 & 4 \\
\hline 51 & & Chentang Bridge & 0.88 & 1.62 & 0.75 & 0.7 & - & 3 & 4 & 4 \\
\hline
\end{tabular}




\begin{tabular}{|c|c|c|c|c|c|c|c|c|c|c|}
\hline 52 & \multirow{10}{*}{$\begin{array}{c}\text { South-North } \\
\text { Water Transfer } \\
\text { East Canal }\end{array}$} & Jiangdu & 0.38 & 0.36 & 0.2 & 0.28 & $\overline{5.96}$ & 3 & 3 & 3 \\
\hline 53 & & Gaoyou & 0.77 & 0.53 & 0.52 & 0.85 & 6.04 & 4 & 4 & 4 \\
\hline 54 & & Baoying & 0.85 & 0.48 & 0.63 & 0.82 & 7.52 & 4 & 4 & 4 \\
\hline 55 & & Huaian & 1.05 & 1.92 & 0.77 & 0.78 & - & 3 & 3 & 3 \\
\hline 56 & & Siyang & 0.48 & 0.37 & 0.26 & 0.45 & 6.19 & 3 & 4 & 4 \\
\hline 57 & & Suqian & 0.59 & 0.46 & 0.34 & 0.59 & 5.99 & 4 & 4 & 4 \\
\hline 58 & & Pizhou & 0.48 & 0.29 & 0.74 & 0.39 & - & 2 & 2 & 2 \\
\hline 59 & & Taierzhuang & 0.77 & 0.53 & 0.44 & 0.76 & 5.98 & 4 & 4 & 4 \\
\hline 60 & & Jining & 0.09 & 0.32 & 0.52 & 0.1 & - & 3 & 3 & 3 \\
\hline 61 & & Liangshan & 0.34 & 0.26 & 0.18 & 0.32 & 8.82 & 2 & 3 & 3 \\
\hline 62 & \multirow{5}{*}{ Hongze Lake } & Laozishan & 0.29 & 0.33 & 0.17 & 0.27 & 6.1 & 3 & 3 & 3 \\
\hline 63 & & Lihewa & 0.53 & 0.28 & 0.29 & 0.49 & 5.98 & 4 & 4 & 4 \\
\hline 64 & & Chengzihu & 0.8 & 0.46 & 0.52 & 0.58 & 7.13 & 4 & 3 & 4 \\
\hline 65 & & Erhezha & 0.57 & 0.27 & 0.49 & 0.66 & 6.04 & 4 & 3 & 4 \\
\hline 66 & & Sanhezha & 0.52 & 0.2 & 0.28 & 0.38 & 5.96 & 3 & 3 & 3 \\
\hline 67 & \multirow{5}{*}{ Nansi Lake } & Weishandao & 0.38 & 0.56 & 0.2 & 0.25 & 5.96 & 4 & 4 & 4 \\
\hline 68 & & Erjibashang & 0.45 & 0.22 & 0.5 & 0.59 & 7.87 & 3 & 3 & 3 \\
\hline 69 & & Erjibaxia & 0.41 & 0.4 & 0.26 & 0.3 & 5.96 & 3 & 3 & 3 \\
\hline 70 & & Nanyang & 0.38 & 0.23 & 0.26 & 0.53 & 7.32 & 3 & 3 & 3 \\
\hline 71 & & Dushandao & 0.03 & 0.05 & 0 & 0.51 & - & 3 & 3 & 3 \\
\hline
\end{tabular}

1 Note: IndH is the ecosystem health degree when the weights of three organisms were $0.50,0.25$,

20.25 , respectively; $\operatorname{IndH}(1)$ is the ecosystem health degree when the weights of three organisms were

$30.33,0.34,0.33$, respectively; $\operatorname{IndH}(2)$ is the ecosystem health degree when the weights of three

4 organisms were $0.50,0.30,0.20$, respectively. The overstriking number in $\operatorname{IndH}(1)$ and $\operatorname{IndH}(2)$

5 columns means the different health degree comparing to InH column.

6 
2 Table 5 The affected of watershed size, dams or sluices and water quality on river 3 ecosystem in the Huai River Basin

\begin{tabular}{lllll}
\hline & Watershed size & Distance & Water quality & Grouping Variable \\
\hline p-value & 0.491 & 0.601 & - & Water quality \\
p- value & 0.427 & $0.003^{*}$ & $0.034^{*}$ & Eco-health \\
\hline
\end{tabular}

4 Note: 'p-value' is a measure of probability and the criterion of statistical significance is 0.05 ; '*' ' is 5 the significant factors.

6

7 
Table 6 The influential factors on river ecosystem in the Huai River Basin

\begin{tabular}{|c|c|c|c|c|c|}
\hline Bio-indictors & Variables & Category & $\mathrm{p}$-value & Prop. & Cumul. Prop \\
\hline \multirow{4}{*}{ Phytoplankton } & SRD & climate & 0.001 & 0.164 & 0.164 \\
\hline & ZERON & hydrology & 0.044 & 0.082 & 0.246 \\
\hline & MINT & climate & 0.005 & 0.078 & 0.324 \\
\hline & RHUM & climate & 0.041 & 0.051 & 0.375 \\
\hline \multirow{6}{*}{ Zooplankton } & SRD & climate & 0.001 & 0.135 & 0.135 \\
\hline & PADDY & landuse & 0.005 & 0.073 & 0.208 \\
\hline & PMMF & hydrology & 0.015 & 0.066 & 0.274 \\
\hline & GRASS & landuse & 0.024 & 0.056 & 0.33 \\
\hline & $\mathrm{NH}_{3}-\mathrm{N}$ & water quality & 0.016 & 0.053 & 0.383 \\
\hline & SMMF & hydrology & 0.04 & 0.04 & 0.423 \\
\hline \multirow{2}{*}{$\begin{array}{l}\text { Benthic } \\
\text { macroinverterbrate }\end{array}$} & $\mathrm{NH}_{3}-\mathrm{N}$ & water quality & 0.015 & 0.128 & 0.128 \\
\hline & ARI10 & hydrology & 0.05 & 0.069 & 0.197 \\
\hline \multirow{4}{*}{ The whole ecosystem } & SRD & climate & 0.001 & 0.131 & 0.131 \\
\hline & PMMF & hydrology & 0.023 & 0.061 & 0.192 \\
\hline & $\mathrm{BI}$ & hydrology & 0.039 & 0.053 & 0.245 \\
\hline & PADS & soil & 0.048 & 0.05 & 0.295 \\
\hline
\end{tabular}

3 Note: 'p-value' is a measure of probability, the tail probability of the distribution of a test statistic in 4 statistical significance testing; 'Prop.' is the proportion of ecology variation affected by the 5 predictor; 'Cumul. Prop.' is the cumulative proportion of ecology variation affected by all the 6 predictors. 


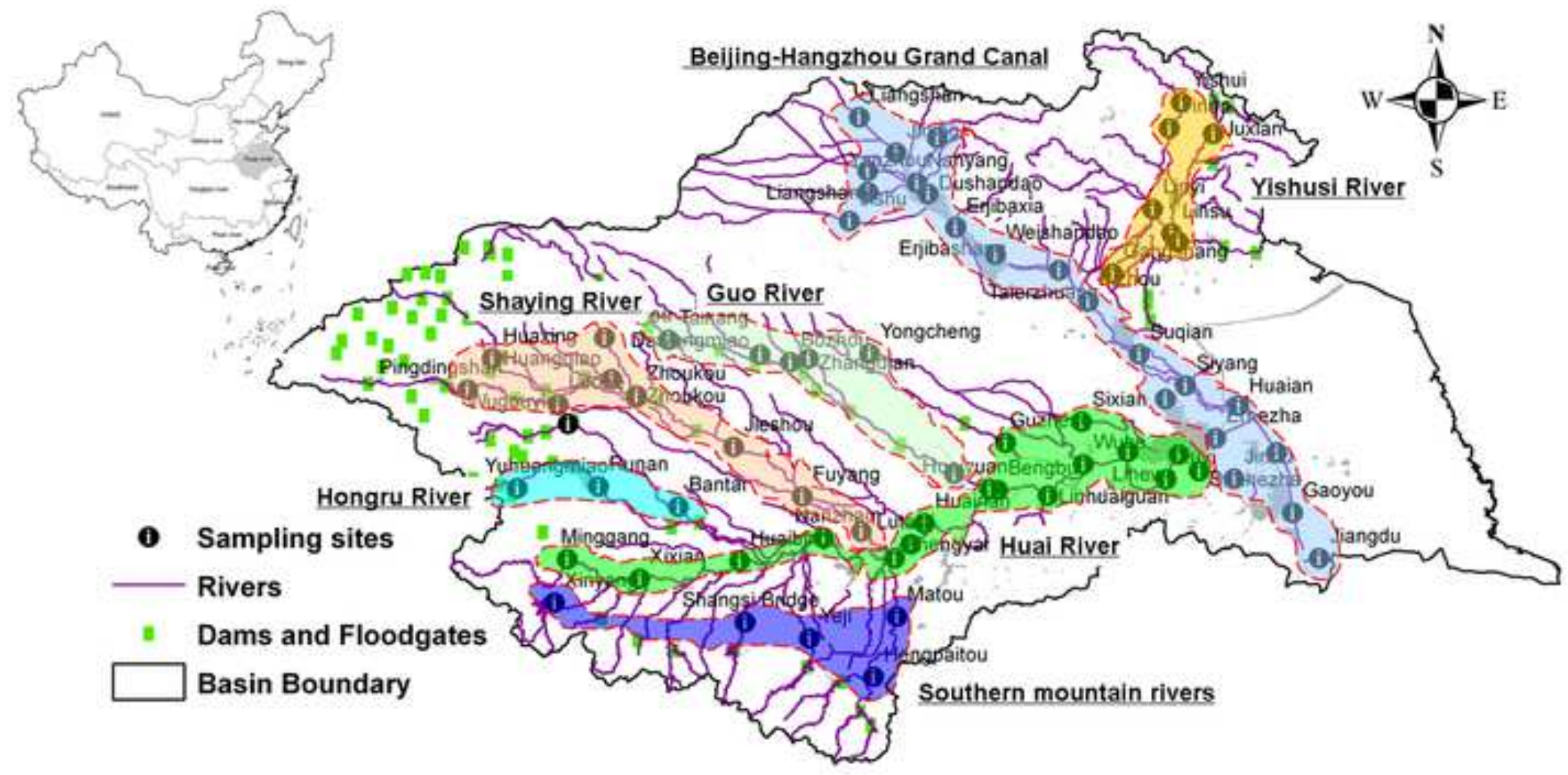



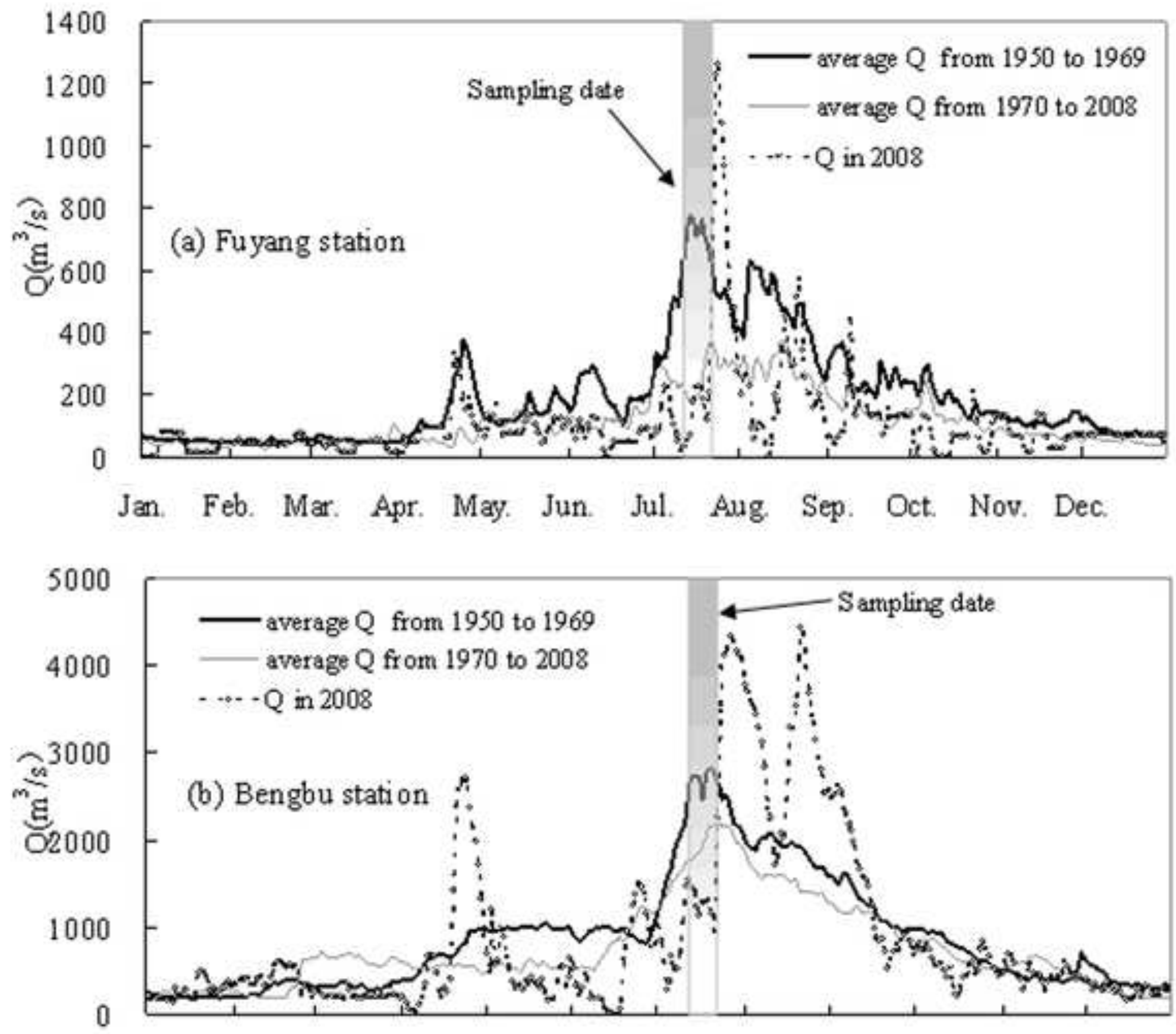

Jan. Feb. Mar. Apr. May. Jun Jul. Aug. Sep. Oct. Nov. Dec. 
Figure 3

Click here to download high resolution image
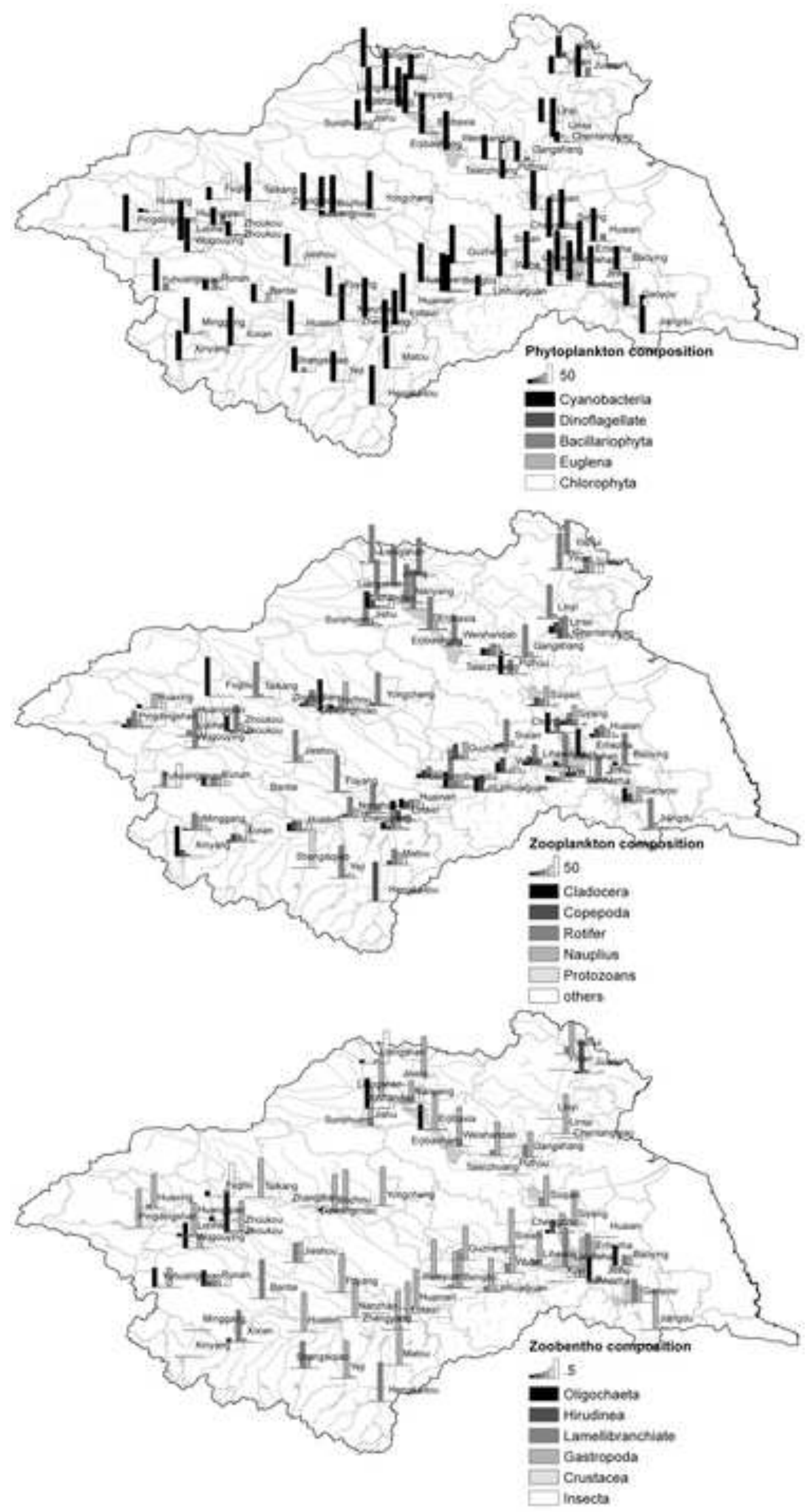


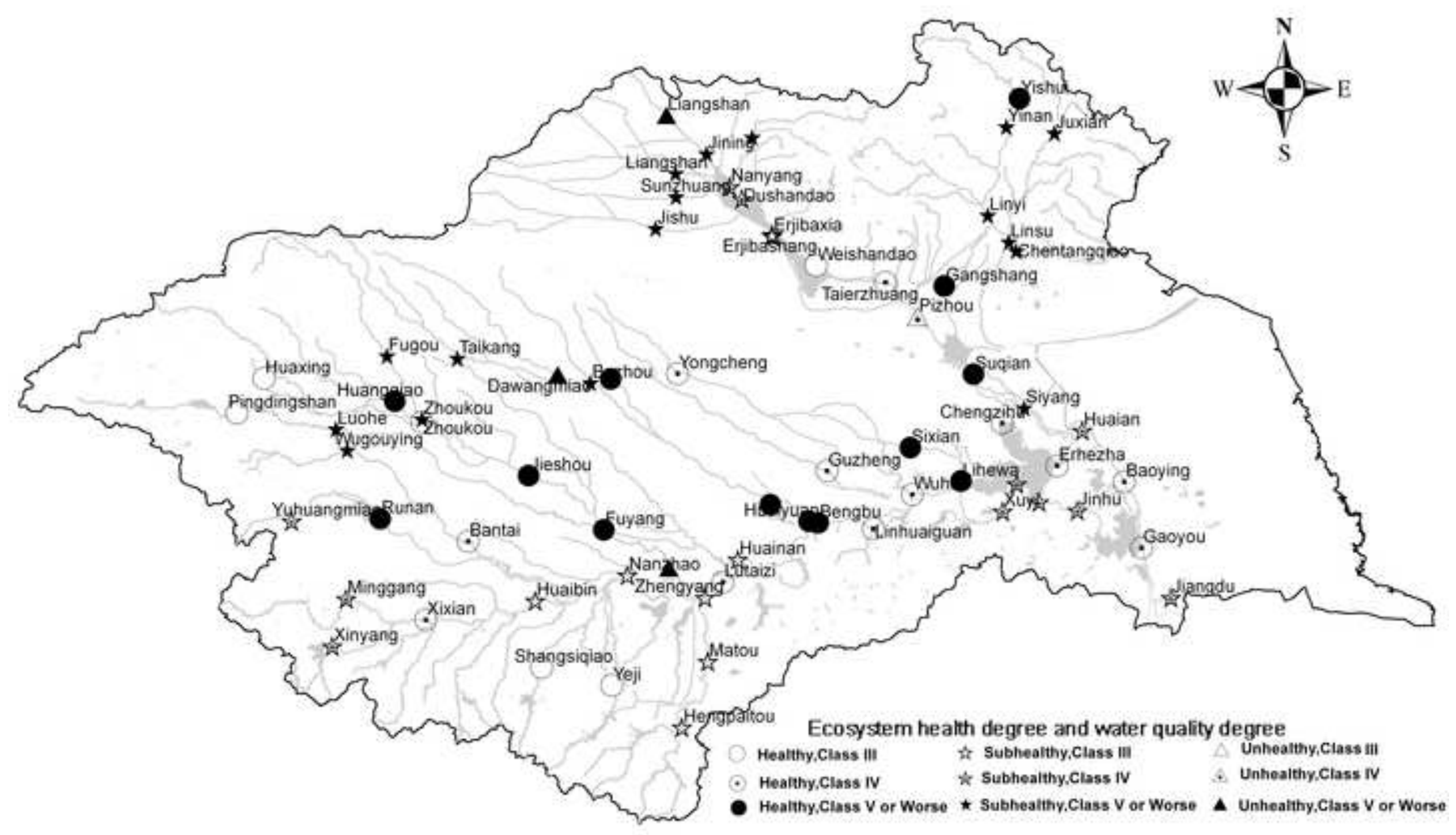


1 Fig.1 Location of the Huai River Basin and sampling sites distribution

2 Fig.2 The comparison of average daily runoff at Fuyang and Bengbu stations in 3 per-dams period (1950-196), post-dams period (1970-2008) and the sample year 4 (2008).

$5 \quad$ Fig.3 The phytoplankton (a), zooplankton (b) and zoobentho(c) composition of all the 671 investigated sites in the Huai River Basin

7 Fig.4 The ecosystem health degree and water quality degree of all the 71 investigated 8 sites in the Huai River Basin 